\title{
Brésil - vieux Portugal, no encontro de Le Corbusier com o Brasil em 1929
}

\author{
João Belo Rodeia \\ rodeiapt@gmail.com \\ Arquiteto | Professor auxiliar convidado do Da/UAL
}

Para citação: ARROYAVE, Lina - Brésil - vieux Portugal, no encontro de Le Corbusier com o Brasil em 1929. Estudo Prévio 17. Lisboa: CEACT/UAL - Centro de Estudos de Arquitetura, Cidade e Território da Universidade Autónoma de Lisboa, 2020. ISSN: 2182-4339 [Disponível em: www.estudoprevio.net]. DOI: https://doi.org/10.26619/2182-4339/17.2

Artigo recebido a 7 de junho de 2020 e aceite para publicação a 19 de junho de 2020. Creative Commons, licença CC BY-4.0: https://creativecommons.org/licenses/by/4.0/

\section{Resumo}

Este artigo delimita-se na hipótese de Le Corbusier (1887-1965) ter constatado Portugal a pretexto do Brasil e, por sua vez, de que tal constatação terá induzido o seu primeiro encontro com terras brasileiras em 1929, vertido em "Précisions sur un état présent de l'architecture et de l'urbanisme" (1930), também fronteira a jusante ao período temporal em análise.

Para o efeito, discrimina-se um conjunto de informações até agora dispersas em fontes disponíveis, que ecoam lastros portugueses ou luso-brasileiros entre a intricada teia de relações parisienses do mestre franco-suíço, incluindo as amizades brasileiras, além do confronto direto com Lisboa na viagem para a América do Sul de 1929. Desta interação, sempre associada a "Précisions", resulta plausibilidade para a hipótese, perfazendo um panorama que remata nas sugestões urbanísticas de Le Corbusier para o Brasil, em particular a carioca, bem como no papel que reserva ao Brésil - vieux Portugal no futuro do Brasil, cujas possibilidades interpretativas abrem caminhos para investigação consequente.

Ainda que limitado à hipótese, o artigo aproxima-se do ensaio, definido como "ciencia, menos la prueba explícita"1 por José Ortega y Gasset (1883-1955) e há muito recurso da reflexão histórica, mais argumentativo que comprovativo, na margem da severidade académica e mais aberto na ordenação dedutiva e didática, também passível de inscrever fatos, circunstâncias, episódios e curiosidades indispensáveis à caracterização de um ponto de vista, bem como de um ambiente potenciador do enredo e respetiva legibilidade.

Palavras-Chave: Le Corbusier, Brasil, Portugal 


\begin{abstract}
Artigo
Em setembro de 1929, Le Corbusier vai abordar Lisboa aquando da travessia atlântica para a América do Sul, com provável reincidência no regresso a França já em dezembro, a dias do Natal. Ao que sabemos, será a sua primeira e única (dupla) passagem por Portugal. Da estada sul-americana - Argentina, Paraguai, Uruguai e Brasil - resultará um livro apaixonado, "Précisions sur un état présent de l'architecture et de l'urbanisme" (1930), crucial testemunho da sua evolução doutrinária na transição dos anos vinte para os trinta, muito induzida, aliás, pelo périplo brasileiro ${ }^{2}$. $E$ o único dos seus textos com pontuais referências a Portugal, diretas e indiretas, se bem que a pretexto do Brasil. Ou seja, Portugal revelar-se-á em Le Corbusier associado ao Brasil numa espécie de dupla viagem: a viagem móvel, a transatlântica com a estada brasileira, e a imóvel, declinada em "Prologue Américain"3 e, sobretudo, em "Corollaire Brésilien"4, ambas inseparáveis, como veremos, de Paulo Prado (1869-1943), o seu melhor amigo brasileiro.
\end{abstract}

A esta viagem há que associar a intrincada teia de relações e conhecimentos de Le Corbusier em Paris durante os anos vinte. Recuando até 1917, ano da sua migração definitiva da suíça La Chaux-de-Fonds para a capital francesa, à época ainda CharlesÉdouard Jeanneret, importa acareá-lo com o pintor Amedée Ozenfant (1886-1966) que Ihe será apresentado por Auguste Perret (1874-1954), seu antigo patrono. Da empatia deste primeiro encontro, fortuito ao que parece, nascerá duradoura relação artística e profissional até 1924, decerto incontornável à sedução do ainda jovem Jeanneret, pois, em 1917, Ozenfant era já pintor de créditos firmados e bem conhecido nos meandros artísticos parisienses. Instalado na cidade-luz desde 1905, formara-se na Académie de la Palette em Montparnasse onde conhecera a ucraniana Sonia Terk (1885-1979), sua grande amiga e futura Delaunay ao casar-se em 1910 com o também pintor Robert Delaunay (1885-1941). O casal conhece então Amadeo de Souza-Cardoso (18871918), entre outros dos pioneiros da modernidade pictórica portuguesa instalados em Paris ${ }^{5}$. Fugidos da guerra, refugiam-se em Portugal entre 1915 e 1916, com passagem por Lisboa e residência em Vila do Conde com o pintor Eduardo Viana (1881-1967) e, após breve estada em Monção, também em Valença do Minho. Além do reencontro com Amadeo, relacionam-se com os artistas José de Almada Negreiros (1893-1970) e José Pacheco (1885-1934), entre tempos felizes e criativos com o sol, o mar e as cores portuguesas. Por iniciativa de Sonia, poemas de Guillaume Apollinaire (18801918) e de Blaise Cendrars (1887-1961) publicam-se na breve revista Portugal Futurista $(1917)^{6}$. Aliás, Cendrars era amigo dos Delaunay e, após o regresso destes a Paris em 1920, não é improvável terem-no aproximado a Portugal. Por sua vez, o poeta será (e manter-se-á) próximo de Le Corbusier. Ambos haviam nascido exatamente no mesmo ano, na mesma localidade suíça e em endereços próximos, mas o convívio seria já parisiense, a partir de $1922^{7}$.

Ozenfant terá papel determinante na afirmação de Le Corbusier como pintor e, sobretudo, como personalidade pública da cidade-luz. Convida-o para ser coautor de "Après le Cubisme", publicado em dezembro de 1918, o primeiro manifesto artístico parisiense do pós-guerra e simultâneo à exposição de ambos na Galerie Thomas. Advogam o Purisme, inseparável da invariabilidade, intemporalidade e transnacionalidade das formas primárias associadas a um tempo novo, que virá a constituir-se como cerne da doutrina arquitetónica corbusiana em quadro machiniste, enriquecida e transformada ao longo da década. Dois anos mais tarde, em 1920, 
PT | P01 | EP17| s2020

fundam com o belga Paul Dermée (1886-1951) a revista L'Esprit Nouveau (19201925), cujo nome ecoava Apollinaire e Paul Valery (1871-1945), onde Le Corbusier vai publicar os textos precursores que informarão "Vers une Architecture" (1923), bestseller internacional a sinalizar alcançada notoriedade.

Através de Ozenfant (e da revista), Le Corbusier trava conhecimento com enorme plêiade de artistas, mas também de galeristas e marchands. Entre muitos outros, além dos Delaunay com os seus quadros portugueses, incluindo, de Robert, "La grande portugaise" (1916), contam-se Georges Braque (1882-1963) com o anterior "Le Portugais" (1911), os espanhóis Juan Gris (1887-1927) ou Pablo Picasso (1881-1973), ou ainda o lituano Jacques Lipschitz (1891-1973) e Fernand Léger (1881-1955), dois dos seus maiores amigos. Todos com obras publicadas na "L'Esprit Nouveau". E também (quase) todos entre os autores dos primeiros quadros modernos que vão chegar a São Paulo (e ao Brasil) a partir do início da década de 20 pelas mãos dos milionários Paulo Prado e Olívia Penteado (1872-1934), ligados à produção cafeeira.

Provável é o conhecimento da "L'Esprit Nouveau" entre o meio artístico português da época em Paris, entre residentes e visitantes, mas sabemo-la bem presente desde a primeira hora em São Paulo, designadamente junto dos escritores Mário de Andrade (1893-1945) e Oswald de Andrade (1890-1954), ambos assinantes, ou das pintoras Anita Malfatti (1889-1964) e Tarsila do Amaral (1886-1973). Aliás, a revista terá sido indutora da célebre Semana de Arte Moderna paulista de 1922, associada à eclosão da vanguarda moderna brasileira, também "nacionalista"8, inseparável da ação promocional e mecenática de Prado e de sua esposa francesa Marinette Prado (?), ou ainda de Penteado, habitués parisienses, que contaria com a presença (e participação) do jovem jornalista e escritor António Ferro (1895-1956), integrante da vanguarda literária e artística portuguesa.

Anote-se que Ferro, amante indefetível de Paris para onde rumava de amiúde e um dos mais cosmopolitas lisboetas na década de vinte, passará larga temporada no Brasil por esta altura, vertida em notoriedade local e estreita proximidade com os assinalados e outros protagonistas, incluindo Ronald de Carvalho (1893-1935), codiretor da breve revista luso-brasileira de vanguarda Orpheu (1915), da qual Ferro havia sido editor. Aliás, casará em São Paulo por procuração com a poetisa lusa Fernanda de Castro (1900-1994) que logo rumaria ao Brasil. Oswald e Tarsila serão seus padrinhos de casamento, com Fernanda a ser imortalizada em quadro da pintora brasileira. Virão depois inúmeros reencontros ao longo da década de vinte, incluindo correspondência periódica com Mário e Oswald, entre outros, com Ferro pelo menos presente na primeira das duas exposições parisienses de Tarsila, na Galerie Percier em 1926, neste mesmo ano com texto sobre a pintora na revista lusa Contemporânea (1922-1926) ${ }^{9}$, pertencendo-lhe outro no catálogo da primeira individual no Brasil, no Palace Hotel do Rio de Janeiro em $1929^{10}$. E já nos anos 30, Tarsila dedicará crónica a livro de poemas de Fernanda ${ }^{11}$, com quem, aliás, mantinha também correspondência.

Tal como os artistas portugueses, também os brasileiros eram atraídos tanto pela possibilidade formativa quanto pela exuberância criativa e boémia de Paris. Tarsila estará por Paris logo em 1920-21, seguida por Anita que aqui viverá a partir de 1922 (até 1928). Em 1923, Tarsila regressa à cidade-luz, desta vez acompanhada por Oswald, seu companheiro sentimental, para logo seguirem para Portugal entre janeiro 
e fevereiro de 1923 - onde reencontrarão Ferro e Fernanda - e Espanha. Importa reter que nesta época as relações entre Portugal e o Brasil (e vice-versa) continuavam intensas. O Brasil, onde a cultura portuguesa persistia presente, era destino principal da emigração portuguesa, também refúgio de aventureiros e desamparados (incluindo intelectuais e políticos). Portugal, por sua vez, onde a cultura brasileira era divulgada e apreciada, além de incontornável aos que estudavam o passado do Brasil, mantinhase destino universitário de gentes brasileiras e Lisboa era o meio caminho dos brasileiros para França e o meio-caminho no regresso à pátria.

O vai e vem marítimo era constante. As principais companhias de navegação, incluindo as francesas, abordavam a capital portuguesa com os seus paquetes na viagem entre a Europa atlântica e a América do Sul (e vice-versa). E no lento travelling da entrada até ao fundear no Tejo, desde Cascais e a Serra de Sintra até à visão frontal da cidade, os embarcados descobriam ou redescobriam Lisboa na sua paisagem, no perfil orográfico, na adequação topográfica e na relação com o rio e o mar que tanto fazia lembrar o coevo sistema urbano de inúmeras cidades litorâneas brasileiras, de Salvador da Bahia ao Rio de Janeiro. A escala lisboeta, ainda sem atracagem, durava muitas horas (os movimentos por lanchas de embarque e desembarque, de carga e descarga, eram lentos e numerosos) e, tal como Lucio Costa (1902-1998) a bordo do Bagé em 1926, havia tempo para deambular pela cidade ${ }^{12}$.

Em "Précisions", Le Corbusier fala de Paulo Prado como o seu maior amigo brasileiro ${ }^{13}$, importando dedicar-Ihe, por isso, atenção acrescida. Oriundo de uma das mais poderosas dinastias paulistas, cuja origem portuguesa remontava ao início do século XVIII, Prado não era apenas um dos inúmeros abonados brasileiros que de amiúde passavam por Lisboa a caminho de Paris. Viajado, culto, colecionador de arte (e amante de livros), viria a ser destacado homme de lettres ao longo dos anos vinte ao refletir sobre o passado e o futuro do seu país (e de São Paulo), fazendo a ponte entre o passado e a modernidade com "brasilidade" de permeio. Aos 20 anos havia rumado à cidade-luz em tempos de Belle Époque, aqui vivendo até ao final do século XIX em plena Rue de Rivoli na residência de Eduardo Prado (1860-1901), seu tio paterno. Homem de gosto refinado e estudioso da história colonial do Brasil, Eduardo terá servido de inspiração para a personagem Jacinto de A Cidade e as Serras (1901) de José Maria Eça de Queiroz (1845-1900), dos seus maiores amigos e também ele parisiense indefetível.

Paulo vai conviver de perto no cenáculo luso-brasileiro de ambos e que reunia ora em Neuilly, na residência de Eça, ora na Rue de Rivoli, e por onde passaram, entre outros portugueses e além de destacadas personalidades brasileiras ${ }^{14}$, o escritor José Ramalho Ortigão (1836-1915) e, sobretudo, o historiador Joaquim de Oliveira Martins (1845-1894), autor de "O Brasil e as Colónias Portuguesas" (1880). Este luso lastro formativo jamais o abandonará. De Eça vai manter a fineza e agudeza críticas e Oliveira Martins será crucial para a sua visão histórica do Brasil e de Portugal ${ }^{15}$, tanto na glorificação dos portugueses de Quinhentos (dos descobridores e dos primeiros colonos), quanto na denúncia da posterior decadência, quanto ainda em esperançada regeneração, uma espécie de regresso aos heróis camonianos, agora projetada na contemporaneidade e no devir do Brasil, na refundação de uma pátria emancipada da Europa, moderna e brasileira, visão esta que, a partir de 1917, será transversal aos seus textos até ao paradigmático Retrato do Brasil - Ensaio sobre a tristeza brasileira (1928). 
Mas há mais. Seu tio incutir-lhe-á o gosto colecionista por antiga documentação relativa à história, geografia e etnografia brasileiras. Tal como ele, será cliente assíduo do antiquário Charles Chadenat (1859-1938) na Librairie Américaine, junto ao parisiense Quai des Grands-Augustins, famosa pelo seu catálogo de livros, mapas e documentos coloniais que incluía secção brasileira. E através de seu tio, iniciará e manterá longeva amizade, convivência e aprendizagem com o historiador brasileiro João Capristano de Abreu (1853-1927), também ele devedor de Oliveira Martins, que sempre privilegiou os caminhos terrestres e fluviais como argumento central da (sua) história colonial, uma vez mais conjugando história e geografia como em Caminhos Antigos e Povoamento do Brasil (1930).

De Capristano decerto provirá muito do conhecimento de Prado sobre inúmeras fontes coevas que vão do "Diário de Navegação", de Pêro Lopes de Sousa 1500-1532 (1927), com introdução do próprio historiador, porventura passando pela pioneira e extraordinária expedição científica do naturalista luso-brasileiro Alexandre Rodrigues Ferreira (1783-1792) ${ }^{16}$, até à "Corografia Brazilica ou Relação histórico-geográfica do Reino do Brazil” (1817) do padre português Manuel Aires de Casal (1754-1821), onde pela primeira vez surge publicada a Carta de Pêro Vaz de Caminha, redescoberta em 1773 na Torre do Tombo. Prado considerava-a como retrato fundador do Brasil "na sua idílica ingenuidade (...), primeiro hino consagrado ao esplendor, à força e ao mistério da natureza brasileira (...)" onde "percebe-se o encantamento do maravilhoso achado que surgia diante dos navegantes depois da longa e incerta travessia" ${ }^{17}$. Uma visão do paraíso, portanto. E, adiante-se, será esta visão do Brasil, a de Prado, que Le Corbusier apreenderá antes e durante a viagem de 1929, tal como havia já acontecido, como veremos, com Cendrars.

A aproximação de ambos ao Brasil tem início em novelo parisiense, na cidade onde o milionário paulista mantinha temporada estival a cada ano. Desde os primeiros anos da década de vinte assiste-se a convivialidade entre o assinalado círculo brasileiro de Paris e o círculo mais íntimo das amizades de Le Corbusier, porventura com ele próprio. Logo após a viagem a Portugal no início de 1923, Tarsila (com Oswald) conhece Cendrars em maio ${ }^{18} \mathrm{e}$, por intermédio deste, também Léger em outubro ${ }^{19}$, frequentando então o seu atelier ${ }^{20}$. Admite-se que Le Corbusier, levado por Cendrars ou Léger, tenha sido conviva da artista brasileira ainda em $1923^{21}$, pois existe retrato respetivo pelo pintor Emiliano Di Cavalcanti (1897-1976) ${ }^{22}$. Será também Tarsila (com Oswald) a intermediar Prado junto de Léger e de Cendrars ${ }^{23}$. Aliás, o pintor francês vai ser dos primeiros a vender quadros a $\operatorname{Prado}^{24}$ (e a Penteado) entre frequente convivialidade de ambos ao longo dos anos vinte ${ }^{25}$. E, por sua vez, de encontro casual na Librairie Américaine, intermediado por Oswald ${ }^{26}$, provirá o convite de Prado para Cendrars visitar o Brasil, concretizado logo em 1924.

Serão assim Léger e, em particular, Cendrars a despertar o Brasil junto de Le Corbusier, entregando-Ihe a visão do círculo brasileiro de Paris. E, sensivelmente a partir de 1925, vão incentivá-lo a visitar o Brasil, sobretudo a pretexto de Planaltina, a anunciada nova capital brasileira ${ }^{27}$. Por seu turno, admite-se o cruzamento de Le Corbusier com Prado no atelier de Tarsila ${ }^{28}$, mas terá sido Léger a aproximá-los por volta de $1926^{29}$, sabendo-se de encontros e contatos a dois desde então ${ }^{30}$, além de outros nos salons frequentados em simultâneo, tais como os da espanhola Isabel Dato Barrenechea (?-1937), Duquesa de Dato, da chilena Eugenia Errazuris (1860-1951) ou da argentina Victoria O'Campo (1890-1979). Provirão deste contexto o convite para 
Le Corbusier conferenciar na Argentina em 1929, intermediado por Alfredo Gonzaléz Garaño (1886-1969) e O'Campo ${ }^{31}$, e a origem de Prado como seu melhor amigo brasileiro.

Em 1924, a bordo do Formose, Cendrars ruma pela primeira vez ao Brasil por conta do mecenas paulista. A amizade mútua, muito estreita, firmar-se-á e será duradoura. Vai regressar em 1926 e 1927, sempre com passagens por Lisboa, a que rumará per si pelo menos em 1929 e em 1934. Será, aliás, o tradutor para francês de A Selva (1930) como "Forêt Vierge" (1938) do escritor português José Ferreira de Castro (1898-1974), fruto de direta experiência no seringal Paraíso em plena floresta amazónica. Ora, a primeira estada de Cendrars no Brasil, cerca de seis meses, resulta em paixão avassaladora, antecipando recíproca de Le Corbusier. Também em sucesso retumbante. Frequenta a mansão-jardim tropical de Prado na paulista Avenida Higienópolis, é honrado nos principais media da cidade, tem direito a conferência lotada no Conservatório Musical de São Paulo, acompanhada de exposição com quadros de Paul Cézanne (1839-1906), Delaunay, Léger, Albert Gleizes (1881-1953), de Tarsila e do lituano-brasileiro Lasar Segall (1891-1957), todos pertença de Prado e Penteado ${ }^{32}$. Visita o salon paulista desta última, convive e diverte-se com a intelligentsia local, é acarinhado e alvo de todas as atenções. Assiste em direto à revolta de 24, vai ao carnaval do Rio de Janeiro com Penteado e o grupo de 22, incluindo Tarsila e Oswald. Com este mesmo grupo, por montes e vales, peregrina pelas cidades históricas de Minas Gerais à descoberta de "brasilidade". Na luxuriante São Martinho, a fazenda cafeeira de Prado perto de Ribeirão Preto, experimenta o calor tropical, dorme na rede da varanda, escreve poesia. Conversam sobre tudo, conversam sobre o Brasil, "Il m'a fait lire tout ces livres, m'initiant à tous ses travaux" 33 , desabafa Cendrars. Será pelo olhar de Prado, o do seu pensamento, que o poeta vai conhecer o Brasil, o do futuro Retrato do Brasil. Contudo, tal como acontecerá em Le Corbusier, de Prado diverge do pessimismo das "três raças tristes" - portuguesa, ameríndia e afronegra - que, para o poeta, são festa, alegria e otimismo. Adora a mistura de gentes e as gentes com mistura. E vai emocionar-se diante da paisagem e das cidades brasileiras como se outras não houvesse, como que regressado à origem de tudo e de partida para um mundo novo. Feliz, faz do Brasil um topos pessoal e íntimo, o (seu) paraíso na terra.

No regresso a França, Cendrars escreve o primeiro livro de Feuilles de Route (1924), ilustrado por Tarsila e dedicado aos seus amigos paulistas e cariocas, com Prado à cabeça. Muitos dos poemas são dedicados ao Brasil e, em 1926, por altura da mencionada individual da pintora na Galerie Percier, associa-Ihes seis dedicados a São Paulo:

"J'adore cette ville, Saint Paul est selon mon cœur, Ici nulle tradition, Aucun préjugé, $\mathrm{Ni}$ ancien ni moderne, Seuls comptent cet appétit furieux cette confiance absolue cet optimisme cette audace ce travail (...) Tout les pays, Tous les peuples, J'aime ça, Les trois vieilles maisons portugaises qui restent, sont des faïences bleues" 34 .

Além de "Pedro Alvarez Cabral", inscrito no ciclo brasileiro, dois dos poemas são dedicados a Portugal, "Porto Leixões" e "Sur les côtes du Portugal": "Du Havre nous n'avons fait que suivre les côtes comme les navigateurs anciens" 35. A incursão de Le Corbusier no Brasil decorreu da oportunidade gerada pelo convite da Asociación Amigos del Arte para Buenos Aires, com apoio da respetiva universidade ${ }^{36}$. Algo de última hora, 
na justa medida da disponibilidade de Prado que a precipitou (e organizou-a) em curtíssimo espaço de tempo ${ }^{37}$. Contudo, esteve longe do improviso. Desde logo, porque a predisposição já existia, incentivada por Léger e, sobretudo, por Cendrars e Prado. Depois, porque Le Corbusier tê-la-á preparado por antecipação, pois "on n'entreprend pas un si long voyage à la légère" 38 , mencionando em "Précisions" e na correspondência materna a documentação brasileira (cartográfica e fotográfica) enviada por Cendrars ${ }^{39}$, além de Feuilles de Route. Depois, ainda, porque tal preparação, incluindo algum conhecimento da história do Brasil $^{40}$, era-Ihe indispensável para saber ao que ia, para potenciar estadas, para configurar conferências, para seduzir interlocutores, pois, como sempre, havia indisfarçável interesse em angariar encomenda: "Que Pierre affûte ses crayons et ses dessinateurs. Nous allons construire l'Amérique" ${ }^{41}$. E além do potencial de São Paulo e do Rio de Janeiro, sabia de Planaltina.

Ora, até à migração para Paris, seria ínfimo o conhecimento de Le Corbusier (ainda Jeanneret) sobre Portugal, também ausente, ao que sabemos, da sua biblioteca pessoal ao invés da vizinha Espanha, desde logo com o "Dom Quijote" (1605) de Miguel de Cervantes (1547-1616), um dos seus livros de cabeceira. Havia, é certo, o "Candide" (1759) de Voltaire (1694-1978), ancorado na catástrofe lisboeta de 1755, aliás mencionado, porventura sob alcance não-inocente, em "Précisions"42. Contudo, em 1929, já Le Corbusier sabia encontrar Portugal no mapa. Claro que ressoavam (escassos) ecos portugueses nos jornais parisienses durante os anos 20, repercutindo, por exemplo, o golpe militar de 26 ou, a partir de 1928, a figura política de Oliveira Salazar (1889-1970). E haviam os Delaunay ou figuras notórias como o jornalista português Homem-Christo Filho (1892-1928), íntimo de Benito Mussolini (1883-1945), que chegaria a presidir ao Syndicat de la Presse Etrangère em Paris, habitué de salons e galerias por onde Le Corbusier circulava. Ou até encontros fortuitos com artistas portugueses residentes ou de visita a Paris. Além das incursões por Espanha, onde, em 1928, aquando das suas conferências madrilenas, ter-se-á cruzado com Almada Negreiros, então residente em Madrid ${ }^{43}$. Ainda assim, o Portugal no mapa provinha sobretudo do Brasil (e de Cendrars). Interesse marginal sem dúvida, mas que favorecia a compreensão do país que desejava conhecer. Em 1929, aquando da viagem, considerava-se pronto para conquistar o Brasil $^{44}$.

A 14 de setembro, pela uma da manhã, Le Corbusier partia de Bordéus a bordo do Massilia $^{45}$, grande paquete da Compagnie de Navigation Sud-Atlantique e, dois dias depois, entrava pelo Tejo, replicando o permeio das viagens de Cendrars ao Brasil. Havia contornado as costas cantábrica e galega, descendo pela portuguesa até Lisboa. As condições meteorológicas eram esplêndidas, estava radiante e, conforme seu hábito, aproveitará para desenhar no carnet de viagem. A partir do convés, conhecem-se esquissos sumários da orla marítima ${ }^{46}$. E entre a entrada e a saída pelo Tejo, porque "il faut savoir être en état de jugement, toujours" ${ }^{7}$, terá constatado algumas das características fundamentais da cidade entre disposição e arrumação orográfica e fluvial, aberta ao mar. As mesmas que encontrará no Rio de Janeiro, se bem que aqui em extraordinária grandeza. Era a primeira vez na Lisboa de "Candide" e sabia-a associada à colonização do Brasil, com a escala a durar tempo mais do que suficiente para poder desembarcar. Presume-se que assim tenha acontecido, pois de Lisboa enviará carta - "cette lettre partira de Lisbonne"48 - a sua mãe e desenhará cena taurina datada da cidade ${ }^{49}$. Porém, desta não fala aparte dos "marsouins (...) à Lisbonne" ${ }^{50}$, os mesmo de Cendrars em "Sur les Côtes du Portugal". Mas a experiência lisboeta decerto ajudá-lo-á a confirmar o Rio como "une ville gaie, portugaise, 
charmante" ${ }^{\text {, }}$, com "boulevards en mosaïque noire et blanche, formant un cirque immense, marqué par (...) la mer qui vient mourir sur une plage fine, contre le trottoir"s?.

Serão cerca de três meses fora de França, dois de périplo sul-americano e um para as duas travessias atlânticas, de Bordéus para Buenos Aires e vice-versa. Apenas chegará à capital argentina a 28 de setembro, após passagem (e desembarque) no Rio de Janeiro, com breve tour noturno pela cidade ${ }^{53}$, depois por Santos, depois ainda por Montevidéu até finalmente alcançar a capital argentina. Sempre a desenhar. Aproveitará a longa viagem para verter em escrita as dez conferências de Buenos Aires ${ }^{54}$, realizadas de 3 a 19 de outubro, uma espécie de suma doutrinária - "C'est une Bible"55 - já na perspetiva de "Précisions"56. Anote-se, contudo, que "Prologue Américain" e "Corollaire Brésilien" acontecerão a posteriori, o primeiro concluído aquando do regresso a França a bordo do Lutetia a 10 de dezembro ${ }^{57}$, e o segundo já em Paris a 27 de janeiro de $1930^{58}$. Ou seja, ambos após a première aérea até Assunção, no Paraguai, momento singular do périplo sul-americano - "voyage formidable sur le centre de l'Amérique. Fleuves colossaux, agrandis par l'inondation: ce sont des bras de mer. Lecture de la nature vierge" 59 -, da visita a Montevidéu e, sobretudo, do confronto com o Brasil. E este de tal forma impactante que Le Corbusier vai decidir-se ao corolário final de "Précisions", a sua Feuille de Route, ao que tudo indica não previsto de início.

Em larga medida, a estada no Brasil replica a de Cendrars, embora concentrada em cerca de três semanas. Mas a paixão será idêntica, também avassaladora. Proveniente de Buenos Aires no paquete Giulio Cesare, onde conhece Josephine Baker (1906-1975), desembarca a 17 de novembro em Santos, seguindo por ferrovia até à Estação da Luz em São Paulo, onde vai permanecer até 2 de dezembro a convite do respetivo Círculo Politécnico. Prado acolhe-o e hospeda-o no Hotel Terminus na Rua Brigadeiro Tobias, bem no centro da cidade. A agenda será intensa ${ }^{60}$. Reunião com o prefeito José Pires do Rio (1880-1950) logo a 19. Duas conferências (pagas) no Instituto de Engenharia, uma sobre arquitetura a 21, levado, neste mesmo dia, pelo russo-brasileiro Gregori Warchavnchik (1896-1972) a visitar as suas pioneiras casas modernas, e outra sobre urbanismo a 26 , não sem antes ser homenageado em sessão da Câmara Municipal a 23 e, também neste dia, com direito a voo pelos céus da cidade pilotado pelo franco-brasileiro Georges Corbisier (1894-?), muito atuante na construção da cidade e amigo de Alberto Santos Dumont (1873-1932), pioneiro da aviação. Desenha, desenha muito. Diverte-se também. A 27 assiste a um show de Josephine Baker e comparece na sua companhia em festa organizada por Warchavnchik. Também com Baker em outra festa (após 25), desta vez em casa de Tarsila e Oswald, com Mário de Andrade à mistura. Gosta da vertiginosa São Paulo, do frenesim, da vitalidade, da toada machiniste, das revoadas de gentes vindas de muitos mundos num só. E sobretudo gosta de Prado, admira-o, aliás o único a prometer-Ihe encomenda, uma nova biblioteca para a sua residência de Higienópolis ${ }^{61}$. Os últimos dias, no fim de semana do dia 30, vão ser passados na Fazenda São Martinho. Continua a desenhar, entre natureza e as coisas primitifs, incluindo as suas gentes. E conversa com Prado. E este fala-Ihe do Brasil, do seu Brasil.

Logo após o regresso a São Paulo, a 2 de dezembro, parte de imediato para o Rio de Janeiro. E o "Rio était le haut et ce haut était couronné comme un feu d'artifice"62, como bem refere logo na primeira página de "Précisions". Um remate, portanto. Serão seis 
dias apenas, mas intensíssimos e em visceral deslumbramento. De novo pela mão de Prado, vai ser acolhido e guiado na capital brasileira pelo seu familiar Antônio Prado Júnior (1880-1955), prefeito da cidade. Hospeda-o no Hotel Glória com vista para o Pão de Açúcar e a praia logo ali:

"je suis accueilli les bras ouverts, je suis heureux, je suis en auto, en canot-moteur, en avion; je nage devant mon hôtel (...); je déambule à pied la nuit; j'ai des amis à chaque minute de la journée, jusque presque au soleil levant; à sept heure du matin, je suis dans l'eau"63.

Nesta roda viva flirta Josephine, convive na "abundância e volúpia das mulatas nos bordéis (...), olha as moças bonitas que passam ao perambular pela noite boêmia nas ruas "destinadas aos marinheiros", ouve o samba no pé dos morros, cheira o aroma da brisa" ${ }^{44}$ do mar. Vai à prefeitura, relaciona-se a com intelligentsia local, incluindo José Graça Aranha (1868-1931) - um dos convivas do cenáculo de Eça e Eduardo Prado - ou Manuel Bandeira (1886-1968), reencontra Tarsila. Anda pela cidade, vê-a de perto. Fala das gentes, fala dos negros "beaux et magnifiques" 65 e das "masques indiens du musée du Rio"66. Sobe aos morros, percorre favelas, vê a paisagem até ao mar. Vai à ilha de Paquetá, em plena baía de Guanabara, vê a paisagem a partir do mar, frontal. Voa de novo e vê a paisagem em síntese, em revelação atmosférica "sur toutes les baies, (...) contourné tous les pics, (...) on est entré dans l'intimité de la ville, (...) tous les secrets qu'elle cachait, (...) on a tout vu, tout compris"67. Desenha compulsivamente, quer compreender o Rio de Janeiro: "sur l'avion, j'ai pris mon carnet de dessin, j'ai dessiné au fur et à mesure que tout me devenait clair"68. E acolhido por Adolfo Morales de los Rios Filho (1887-1973), presidente do então Instituto Central de Arquitetos, profere duas conferências (pagas) na Escola Nacional de Belas Artes na avenida Rio Branco, a 5 e 8 de dezembro, a primeira sobre arquitetura e a última, na véspera da partida para França, sobre urbanismo com ousadíssima sugestão urbanística para a cidade. Será sobretudo esta a informar "Corollaire Brésilien", com oito das respetivas quinze páginas reservadas ao Rio de Janeiro ${ }^{69}$. Dias inesquecíveis, tão inesquecíveis que terão direito à mais feérica prosa alguma vez escrita por Le Corbusier:

"Quand tout est une fête, quand après deux mois et demi de contrainte et de repliement, tout éclate en fête; quand l'été tropical fait jaillir des verdures au bord des eaux bleues, tout autour des rocs roses; quand on est à Rio-de-janeiro"70.

Assim inicia o corolário, repercutindo tanto o émerveillement quanto a mise-en-scène desafiadora e incitante. Desafiadora porque imprestável ao acolhimento de qualquer dos seus prévios desenhos urbanísticos, senão mesmo da doutrina subjacente, e incitante no sentido do repensar e do convidar à ação. Se "Précisions" é uma suma doutrinária, o respetivo "Corollaire Brésilien" é tanto um remate quanto o princípio de novo caminho que a sugestão urbanística para o Rio de Janeiro inicia: "ce corollaire commente un état de tension naissante en ces lieux de croissance précipitée: l'urbanisme"71. Ou seja, o novo tempo anunciado na última página de "Précisions", o dos "Grands Travaux"72, traduzido em mutação doutrinária - e em transmutação puriste - mais tarde consubstanciada em "La Ville Radiueuse" (1935). Le Corbusier tem plena consciência de que algo há de novo, também por isso presume-se ele próprio descobridor, também por isso afirma que "après deux mois et demi de contrainte et de repliement, tout éclate en fête". Há um antes e um depois. 
Perguntar-se-á neste momento: e o que tem Portugal a ver com tudo isto? Porventura nada. Mas não deixa de ser certo, como vimos, que o desafio e o incentivo do Rio de Janeiro vão implicar, por parte de Le Corbusier, intensíssimo escrutínio da cidade, atenção redobrada:

\begin{abstract}
"Les rues de la ville s'en vont vers l'intérieur, dans les estuaires de terre plate entre les montagnes tombant des hauts plateaux; les hauts plateaux seraient comme le dos d'une main s'écrasant grande ouverte, au bord de la mer; les montagnes qui descendent sont les doigts de la main ; ils touchent à la mer; entre les doigts des montagnes, il y a les estuaires de terre, et la ville est dedans; une ville gaie, portugaise, charmante"73.
\end{abstract}

A cidade alegre, charmosa e portuguesa que, ao invés do expectável, é preservada na sua sugestão urbanística. A cidade vertida em disposição e arrumação orográfica, alinhada pela costa, mergulhante nos vales, galgando encostas, aberta ao mar. E o mar do Rio de Janeiro "est une carte de géographie du temps de la conquête, avec les golfes, les montagnes, les navires" ${ }^{\prime 4}$. Dir-se-ia que o Rio de Janeiro é sublime epifania lisboeta.

Mas há outro lado menos óbvio. Mesmo que predisposta e decantada pela formação de Le Corbusier (ainda Jeanneret), bem como pela sua biblioteca ${ }^{75}$, a visão do Brasil latente em "Précisions" coincide com a de Prado, de firme matriz luso-brasileira, também a de Cendrars. É a de Vaz de Caminha e do paraíso, do elogio à natureza, da geografia e dos caminhos fluviais e terrestres, mas igualmente da emancipação europeia e de uma modernidade em simultâneo moderna e brasileira. Todas perpassam pelo livro. Na heroica admiração pelos descobridores e desbravadores portugueses ou luso-brasileiros, "on les voit un peu comme des dieux: n'est-ce pas, Homère?"76, "quel courage, quelle initiative, quelle persévérance!"77, "un puissant levier de stimulation malgré même ses horreurs, ses massacres inexorables, ses destructions décrétées au nom de Dieu"78, personificando-a em "J'ai tenté la conquête de l'Amérique par une raison implacable et par une grande tendresse"79. Ou no émerveillement diante da paisagem vierge et verte, primitif, rendido "ao esplendor, à força e ao mistério da natureza brasileira" onde, tal como em Caminha, "percebe-se o encantamento do maravilhoso achado que surgia diante dos navegantes depois da longa e incerta travessia". Uma aparição, é a visão do paraíso. E porque inesperada, antecipa-se em intensidade na première aérea até Assunção com

\footnotetext{
"le fleuve Paraguay qui est ici à la fin de sa course, à son confluent avec le Parana, et qui remonte indéfiniment vers le nord, dans le forêt vierge du Brésil, jusque tout près de l'Amazone. Le cours de ces fleuves, dans ces terres illimitées et plates, développe paisiblement l'implacable conséquence de la physique; c'est la loi de la ligne de plus grande pente et puis, si tout est devenu plat, c'est le théorème émouvant du méandre. (...) J'ai baptisé ce phénomène, la loi du méandre" 80
}

reconfirmada a partir do vol d'oiseau sobre São Paulo e, sobretudo, sobre o Rio de Janeiro. Aliás, apenas nas conferências brasileiras vai mencionar a loi du meandre, "ce miraculeux symbole pour introduire mes propositions de reformes urbaines ou architecturales" $" 1$, declinando a respetiva lógica no (seu) Brasil, onde "les estuaires de terre plate entre les montagnes tombant des hauts plateaux; les hauts plateaux seraient comme le dos d'une main s'écrasant grande ouverte, au bord de la mer ; les montagnes qui descendent sont les doigts de la main ; ils touchent à la mer ; entre les 
doigts des montagnes, il y a les estuaires de terre, et la ville est dedans" ${ }^{2}$, onde "Le site entier se mettait à parler, sur eau, sur terre et dans l'air" ${ }^{83}$, onde "il y a des origines lointaines à ces routes qui viennent se nouer en ville" 84 . Isto é, com natureza, geografia e caminhos terrestres e fluviais a replicar o argumento central de Caminhos Antigos e Povoamento do Brasil e de muita outra da historiografia colonial brasileira, aliás fundamento das próprias sugestões urbanísticas de Le Corbusier para São Paulo e o Rio de Janeiro, pois são "caminhos" os longos viadutos habitados propostos para uma e outra, no caso carioca com a respetiva sinuosidade geográfica a lembrar o coevo sistema de arruação, agora em versão machiniste.

Como em Prado, não falta em "Précisions" a exortação à hora iminente do Brasil, à precipitação emancipada do seu próprio destino: "Votre destin est d'agir maintenant" Contudo, existem algumas nuances. Le Corbusier gosta da "coisa exótica que vemos pelas ruas" 86 e, tal como Cendrars, afasta-se das "três raças tristes" enquanto óbice ao devir do moderno e brasileiro. Neste contexto, manifesta apreço pela "antropofagia" 87 dos jovens de São Paulo enquanto "communion avec les forces les meilleures"88, enquanto deglutição da "chair même de ses propres ancêtres"89, enquanto "adhésion aux principes heroïques dont le souvenir est encore présent" incluindo a ancestralidade portuguesa, exclamando que "un tel sursaut de courage n'est pas inutile là-bas" ${ }^{1}$. Contudo, nem apreço é plena adesão, nem é absoluta a emancipação diante da Europa equacionada em "Précisions", mas apenas a que respeita ao expurgo do historicismo, do academismo, do urbanismo da Societé Française des Urbanistes e de tudo quanto considera retrógrado, pois Paris mantémse "le lieu des championnats ou des gladiateurs (...) qui établit le dogme du moment. Paris est un sélectionneur"92. Ou seja, Paris é incontornável ao novo tempo brasileiro, leia-se, Le Corbusier considera-se indispensável ao Brasil, quer dirimir "les scrupules, les doutes, les hésitations et les raisons qui motivent l'état actuel" e assim "l'architecture naitra" 93 .

De igual modo e em jeito de conclusão, não há absoluta emancipação do Brasil face ao legado português ou luso-brasileiro. Le Corbusier não opõe propriamente o Brésil - vieux Portuga94 ao novo Brasil, pois o primeiro tem "un puissant levier de stimulation", aliás um dos estímulos para o moderno e brasileiro que, em breve, provirá da fértil doutrinação arquitetónica de Lucio Costa ${ }^{95}$. E, a par, Le Corbusier entrega estatuto homérico aos descobridores e desbravadores pioneiros - "on les voit un peu comme des dieux: n'est-ce pas, Homère?" -, assim transpostos para a odisseia de Ulisses, isto é, para o berço cultural do Mediterrâneo, há muito seu tour de force. É o mundo do "jeu savant, correct et magnifique des volumes assemblés dans la lumière"96, do esprit grec e da grâce latine. Para Le Corbusier, o Brésil - vieux Portugal, porque depositário de mediterraneidade e latinidade, reemerge no devir moderno e brasileiro. Neste sentido, Portugal perpassa nas derradeiras palavras de "Corollaire Brésilien", também as últimas do presente artigo:

"vous êtes, en Amérique du Sud, dans un pays vieux et jeune; vous êtes des jeunes peuples et vos races sont vieilles. Votre destin est d'agir maintenant. Agirez-vous sous le signe despotiquement sombre du hard-labour? Non, je le souhaite, vous agirez en Latins qui savent ordonner, ordonnancer, apprécier, mesurer, juger et sourire" 97 . 
1 José Ortega y Gasset - Meditaciones del Quijote. Madrid: Aguilar, 1975 [1914]. p. 36-37.

${ }^{2}$ Carlos Martins - Uma Leitura Crítica, in Le Corbusier, Precisões sobre um estado presente da arquitetura e do urbanismo. São Paulo: Cosac \& Naify, 2004 [1930]. p. 265-287.

${ }^{3}$ Prologue Américain, in Le Corbusier - Précisions sur un état présent de l'architecture et de l'urbanisme. Paris: Altamira, 1994 [1930]. p. 01-22.

${ }^{4}$ Corollaire Brésilien, ibidem. p. 233-245.

${ }^{5}$ Rui Afonso Santos - O Primeiro e o Segundo Modernismos, in Lapa, Pedro; Tavares, Emilia (coord.) - Arte Portuguesa do Século XX - 1910-1960. Lisboa: MNAC, 2011. p. XXVII-XXXVI.

${ }^{6}$ Portugal Futurista, № 01. Lisboa: Novembro 1917. p. 20, 24.

7 Margareth da Silva Pereira - Le Corbusier au Brésil ou les expériences romantiques de la nature, in Thierry Paquot; Pierre Gras (coord.) - Le Corbusier voyager. Paris: L'Harmattan, 2008. p. 105-106.

${ }^{8}$ No sentido da busca por "brasilidade", para ser, em simultâneo, moderna e brasileira.

${ }^{9}$ António Ferro - Tarsila do Amaral, in Contemporânea, 3ª série, ํㅡㅇㅡ. Lisboa: junho 1926. p. 84-85.

${ }^{10}$ Aracy Amaral (org.) - Tarsila Cronista. São Paulo: Universidade de São Paulo, 2001. p. 475.

11 Tarsila do Amaral - Fernanda de Castro (1937). Ibidem. p. 115-117.

12 Lisboa (carta perdida), in Lucio Costa - Registro de uma vivência, $3^{\text {a }}$ edição revista. São Paulo: SESC e editora 34, 2018 [1995]. p.37. Lucio Costa refere ter visitado o Mosteiro dos Jerónimos, o Museu dos Coches e o Museu Nacional de Arte Antiga durante a manhã, com almoço no restaurante Leão d'Ouro, durante a tarde pelo Chiado de compras nos antiquários na Rua do Alecrim, de regresso ao Bagé ao fim do dia.

${ }^{13}$ Le Corbusier - op. cit. p. 15.

${ }^{14}$ Incluindo Afonso de Melo Franco (1868-1916), Domício da Gama (1862-1925), José Graça Aranha (1868-1931), José da Silva Paranhos Júnior - Barão do Rio Branco (1845-1912), João Capristano de Abreu (1853-1927), Joaquim Nabuco (1849-1910) ou Olavo Bilac (1865-1918).

${ }^{15}$ Conforme assinala Paulo Franchetti, Oliveira Martins vai ter firme e duradoura influência no Brasil. Paulo Franchetti - Estudos de Literatura Brasileira e Portuguesa. São Paulo: Ateliê Editorial, 2007. p. 113-134.

${ }^{16}$ Recorde-se que Alexandre Rodrigues Ferreira, muito esquecido pela historiografia, realizou pioneira expedição científica no Brasil, de 1783 a 1792, percorrendo cerca de 40000 quilómetros, desde Belém do Pará, ao Rio Negro, Mato Grosso e Cuiabá, pela bacia do rio Amazonas e regiões adjacentes, até às fronteiras da Guiana, da Venezuela, da Colômbia, da Bolívia e do Paraguai, recolhendo milhares de espécimes de botânica, zoologia, mineralogia, geologia e antropologia, com forte impacto no meio científico europeu. Foi o mais destacado naturalista luso-brasileiro da sua época.

17 Paulo Prado - Retrato do Brasil, Ensaio sobre a tristeza brasileira, 10 edição. São Paulo: Companhia das Letras, 2012 [1928]. p. 42.

18 Stephanie d'Alessandro; Luis Pérez Oramas - Tarsila do Amaral: inventing Modern Art in Brazil. Chicago: Art Instituto of Chicago, 2017. p. 126.

19 Ibidem. p.126.

${ }^{20}$ Frequentará igualmente os ateliers de André Lhote (1885-1962) e Albert Gleizes (1881-1953), ambos filhos diletos da L'Esprit Nouveau.

${ }^{21}$ Cecília Rodrigues dos Santos; Margareth Campos da Silva Pereira; Romão Veriano da Silva Pereira; Vasco Caldeira da Silva - Le Corbusier e o Brasil. São Paulo: Tessela/ Projeto Editora, 1987. p.32. Margareth da Silva Pereira - Le Corbusier au Brésil ou les expériences romantiques de la nature, in Thierry Paquot; Pierre Gras (coord.), Le Corbusier voyager. Paris: L'Harmattan, 2008. p. 106.

${ }^{22}$ Margareth da Silva Pereira - op. cit. p. 106.

23 Thaís Chang Waldman - Espaços de Paulo Prado: tradição e modernismo. Revue Artelogie, Dossier thématique: Brésil, questions sur le modernisme, no 01. 2011. [23 Junho 2020]. 
Disponível em http://cral.in2p3.fr/artelogie/spip.php?article66.

${ }^{24}$ Carlos Berriel - Tietê, Tejo, Sena: a Obra de Paulo Prado [Texto policopiado]. Campinas: Universidade Estadual de Campinas, 1994. Dissertação de Doutoramento. p. 66.

25 Thaís Chang Waldman - op. cit.

${ }^{26}$ Carlos Berriel - op. cit. p. 27.

${ }^{27}$ Cecília Rodrigues dos Santos; Margareth Campos da Silva Pereira; Romão Veriano da Silva Pereira; Vasco Caldeira da Silva - op. cit. p.16, 33-34, 41, 42.

${ }^{28}$ Margareth da Silva Pereira - op. cit. p.106.

${ }^{29}$ Cecília Rodrigues dos Santos; Margareth Campos da Silva Pereira; Romão Veriano da Silva Pereira; Vasco Caldeira da Silva - op. cit. p.33 e 41.

30 lbidem. p. 42-43.

${ }^{31}$ Le Corbusier - op. cit. p. 19.

${ }^{32}$ Aracy Amaral - Textos do Trópico de Capricórnio (amigos e ensaios 1980-2005), Volume 01. São Paulo: Editora 34, 2009. p. 110.

${ }^{33}$ Branca Alem - As Amizades Brasileiras de Blaise Cendrars: uma análise da Feuilles de Route [Texto policopiado]. Belo Horizonte: Universidade Federal de Minas Gerais, Faculdade de Letras, 2011. Dissertação do Programa de Pós-Graduação em Estudos Literários. p. 125.

${ }^{34}$ Blaise Cendrars - Poésies Complètes. Paris: Denöel, 2005 [1947]. p. 233.

35 Ibidem. p. 198.

36 Le Corbusier terá decidido ir a Buenos Aires em Maio de 1929, ou seja, cerca de quatro meses antes da viagem. A 7 de Maio de 1929 escreve a Cendrars pedindo intermediação para ir também ao Brasil. E apenas a 28 de Julho escreve a Prado com o mesmo intuito. Cecília Rodrigues dos Santos; Margareth Campos da Silva Pereira; Romão Veriano da Silva Pereira; Vasco Caldeira da Silva - op. cit. p. 43, 44.

37 Apenas a 21 de Setembro de 1929, Prado dá por garantida a Le Corbusier uma conferência para São Paulo. Ibidem. p. 34, 45.

${ }^{38}$ Le Corbusier - op. cit. p. 20.

39 Ibidem. p.19-20. Remi Baudouï; Arnaud Dercelles (org.) - Le Corbusier correspondance, Lettres à la famille 1926-1946. Gollion: Infolio, 2013. p. 239.

40 "L'étude de l'histoire manifestée si diversement et si utilement par les documents écrits (...) me semble devoir être le solide fondement d'une éducation intelligente", in Le Corbusier, op. cit. p.15.

${ }^{41}$ Remi Baudouï; Arnaud Dercelles (org.), op. cit. p. 244.

42 Le Corbusier - op. cit. p. 10.

${ }^{43}$ João Belo Rodeia - Ventos de Espanha e Le Corbusier: José de Almada Negreiros em Madrid e as visitas de Jorge Segurado e de Carlos Ramos [Texto policopiado]. Lisboa: Instituto Superior Técnico, 2017. Dissertação da Unidade curricular de Cultura Arquitetónica, Programa Doutoral em Arquitetura.

${ }^{44}$ Remi Baudouï; Arnaud Dercelles (org.) - op. cit. p. 19.

45 Os paquetes Massilia e Lutetia exploraram a linha do Atlântico Sul da Compagnie de Navigation Sud-Atlantique até à Segunda Grande Guerra. A partir de Bordéus, faziam escalas em Vigo, Lisboa, Rio de Janeiro, Santos, Montevidéu e Buenos Aires, com rota inversa a partir desta última cidade. Em Portugal, a Compagnie de Navigation Sud-Atlantique era representada pela Orey Antunes \& CIA Lda. (1886-). Le Corbusier regressaria do Rio de Janeiro para França a bordo do Lutetia.

${ }^{46}$ Le Corbusier - Carnets, Volume 1, 1914-1948. Paris: Herscher, Dessaine et Tolra, 1981. Juan José Lahuerta - Le Corbusier e la Spagna, con la riproduzione dei carnets Barcelone e C10 di Le Corbusier. Milão: Electa, 2006.

47 Le Corbusier - op. cit. p. 13.

48 Remi Baudouï; Arnaud Dercelles (org.) - op. cit. p. 235.

49 Juan José Lahuerta - op. cit. p.25, 27.

${ }^{50}$ Remi Baudouï; Arnaud Dercelles (org.) - op. cit. p.243.

51 Le Corbusier - op. cit. p.234.

${ }^{52}$ Remi Baudouï; Arnaud Dercelles (org.) - op. cit. p.241. 


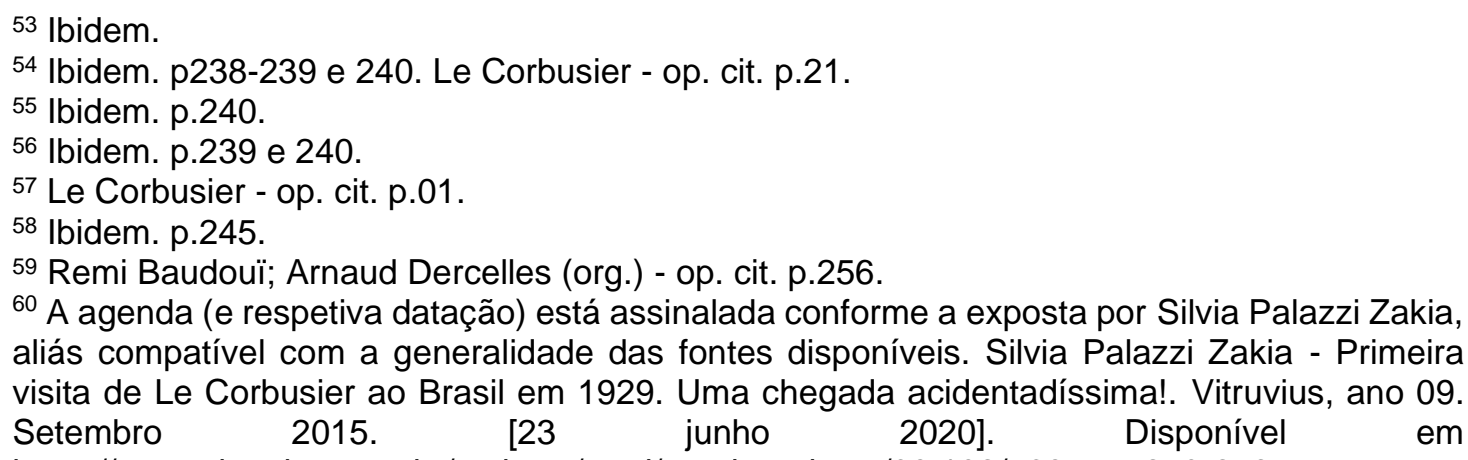
https://www.vitruvius.com.br/revistas/read/arquiteturismo/09.102/5685. p. 270-273.

61 Cecília Rodrigues dos Santos; Margareth da Silva Pereira; Romão da Silva Pereira; Vasco Caldeira da Silva - op. cit. p. 50.

62 Le Corbusier - op. cit. p. 01.

63 Ibidem. p. 234.

64 Daniela Ortiz dos Santos; Mário Luís Magalhães - Le Corbusier voyager, arquivos de uma experiência arquitetônica. Interdisciplinaridade e experiências em documentação e preservação do patrimônio recente. Atas do 9ํㅗㄴ Seminário Docomomo Brasil. Brasília: Docomomo Brasil, 2011. [23 junho 2020]. Disponível em https://docomomo.org.br/wpcontent/uploads/2016/01/161_M24_RM-LeCorbusiervoyageur-ART_daniela_santos.pdf.

65 Le Corbusier - op. cit. p. 10 .

66 Ibidem. p. 12.

67 Ibidem. p. 235.

68 lbidem. p. 236.

69 Refira-se, aliás, que "Corollaire Américain" é apresentado em "Précisions" como a conferência carioca de urbanismo do dia 8 de dezembro. Ibidem. p. 233.

70 lbidem.

71 lbidem: s/p (Avertissement).

72 Ibidem. p. 269.

73 Ibidem. p. 234.

74 lbidem.

75 Além de Voltaire, Le Corbusier refere, por exemplo, Jean-Jacques Rousseau (1712-1778) e Michel de Montaigne (1533-1592). Ibidem. p. 11.

76 Ibidem. p. 15.

77 Ibidem.

78 lbidem.

79 lbidem. p. 19.

80 Ibidem. p. 04-05.

81 Ibidem. p. 05.

82 lbidem. p. 234.

83 lbidem. p. 245.

84 Ibidem. p. 240.

85 Ibidem. p. 245.

86 Lucio Costa - O arranha-céu e o Rio de Janeiro (1928), in Ana Luiza Nobre (org) - Lucio Costa. Rio de Janeiro: Azougue Editorial, 2010. p. 25.

87 Le Corbusier refere-se ao Manifesto Antropófago (1928), proclamado por Oswald de Andrade, que reflete a questão da dependência cultural no Brasil ao valorizar a antropofagia ameríndia como procedimento para criação cultural autóctone, autenticamente brasileira. A deglutição de culturas, incluindo a portuguesa, a africana ou quaisquer outras, aproximava-se da miscigenação, agora a partir do passado pré-cabralino.

88 Le Corbusier - op. cit. p. 17.

89 Ibidem.

90 lbidem. 


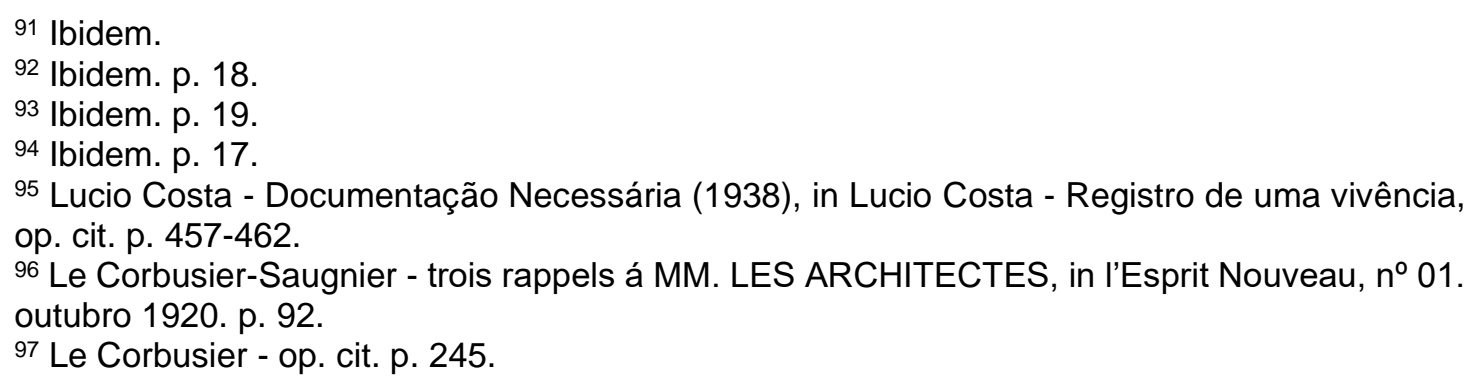

\section{Bibliografia}

ALEM, Branca - As Amizades Brasileiras de Blaise Cendrars: uma análise da Feuilles de Route [Texto policopiado]. Belo Horizonte: Universidade Federal de Mi9nas Gerais, Faculdade de Letras, 2011. Dissertação do Programa de Pós-Graduação em Estudos Literários.

ALESSANDRO, Stephanie; PÉREZ ORAMAS, Luis - Tarsila do Amaral: inventing Modern Art in Brazil. Chicago: Art Instituto of Chicago, 2017. ISBN: 978-0-300-22861-8.

AMARAL, Aracy - Textos do Trópico de Capricórnio (amigos e ensaios 1980-2005), Volume 01. São Paulo: Editora 34, 2009. ISBN: 978-85-7326-364-0.

AMARAL, Aracy (org.) - Tarsila Cronista. São Paulo: Universidade de São Paulo, 2001. ISBN: 978-85-3140-607-2.

BAUDOUÏ, Remi; DERCELLES, Arnaud (org.) - Le Corbusier correspondance, Lettres à la famille 1926-1946. Gollion: Infolio, 2013. ISBN: 978-2-88474-259-7.

BERRIEL, Carlos - Tietê, Tejo, Sena: a Obra de Paulo Prado [Texto policopiado]. Campinas: Universidade Estadual de Campinas, 1994. Dissertação de Doutoramento.

CENDRARS, Blaise - Poésies Complètes. Paris: Denöel, 2005 [1947]. ISBN: 2-20725-271-X.

COSTA, Lucio - Registro de uma vivência, 3ª edição revista. São Paulo: SESC e editora 34, 2018 [1995]. ISBN: 978-85-7326-720-4.

EULALIO, Alexandre (org.) - A Aventura Brasileira de Blaise Cendrars, $2^{\text {a }}$ edição revista e ampliada. São Paulo: Editora da Universidade de São Paulo, 2001. ISBN: 978-85-3140553-2.

FRANCHETTI, Paulo - Estudos de Literatura Brasileira e Portuguesa. São Paulo: Ateliê Editorial, 2007. ISBN: 978-85-74803-53-1.

GUERRA, Abilio - O primitivismo em Mário de Andrade, Oswald de Andrade e Raul Bopp. Origem e conformação no universo intelectual brasileiro. São Paulo: Romano Guerra, 2010. ISBN: 978-85-88585-24-9.

HARRIS, Elizabeth Davis - Le Corbusier - Riscos Brasileiros. São Paulo: Nobel, 1987. ISBN: 978-85-21304-69-2.

LAHUERTA, Juan José - Le Corbusier e la Spagna, con la riproduzione dei carnets Barcelone e C10 di Le Corbusier. Milão: Electa, 2006. ISBN: 88-370-4140-3.

LE CORBUSIER - Carnets, Volume 1, 1914-1948. Paris: Herscher, Dessaine et Tolra, 1981.

LE CORBUSIER - Une maison, un palais. Paris: Connivences, 1989 [1928]. ISBN: 2-86649016-9.

LE CORBUSIER - Précisions sur un état présent de l'architecture et de l'urbanisme. Paris: Altamira, 1994 [1930]. ISBN: 2-909893-06-5.

LE CORBUSIER - Vers une architecture. Paris: Flammarion, 1995 [1923]. ISBN: 978-2-80121744-7.

LE CORBUSIER - La Ville radieuse. Boulogne-sur-Seine: Éditions de l'Architecture d'aujourd'hui, 1935.

LE CORBUSIER; JEANNERET, Pierre - Oeuvre Complète 1929-1934, 15 edição. Basileia, Boston, Berlim: Birkhäuser, 2006 [1934]. ISBN: 978-3-7643-5504-3.

LE CORBUSIER-SAUGNIER - Trois rappels á MM. LES ARCHITECTES. L'Esprit Nouveau, $n^{\circ}$ 01. outubro 1920. p. 91-96. 
LUCAN, Jacques (dir.) - Le Corbusier, une encyclopédie. Paris: Centre George Pompidou, 1987. ISBN: 2-85850-398-2.

MARTINS, Carlos - Uma Leitura Crítica, in Le Corbusier, Precisões sobre um estado presente da arquitetura e do urbanismo. São Paulo: Cosac \& Naify, 2004 [1930]. ISBN: 85-7503290-9. p.265-287.

NOBRE, Ana Luiza (org.) - Lucio Costa. Rio de Janeiro: Azougue Editorial, 2010. ISBN: 97885-79200-32-8.

PEREIRA, Margareth da Silva - Le Corbusier au Brésil ou les expériences romantiques de la nature, in Paquot, Thierry; Gras, Pierre (coord.) - Le Corbusier voyager. Paris: L'Harmattan, 2008. ISBN: 978-2-296-05238-3. p.105-123.

PRADO, Paulo - Retrato do Brasil, Ensaio sobre a tristeza brasileira, 10ª edição. São Paulo: Companhia das Letras, 2012 [1928]. ISBN: 978-85-35920-22-2.

RODEIA, João Belo - Ventos de Espanha e Le Corbusier: José de Almada Negreiros em Madrid e as visitas de Jorge Segurado e de Carlos Ramos [Texto policopiado]. Lisboa: Instituto Superior Técnico, 2017. Dissertação da Unidade curricular de Cultura Arquitetónica, Programa Doutoral em Arquitetura.

SANTOS, Cecília Rodrigues dos; PEREIRA, Margareth da Silva; PEREIRA, Romão da Silva; SILVA, Vasco Caldeira da - Le Corbusier e o Brasil. São Paulo: Tessela/ Projeto Editora, 1987.

SANTOS, Daniela Ortiz; MAGALHÃES, Mário Luís - Le Corbusier voyager - arquivos de uma experiência arquitetônica. Interdisciplinaridade e experiências em documentação e preservação do patrimônio recente. Atas do 9o Seminário Docomomo Brasil. Brasília: Docomomo Brasil, 2011. [23 junho 2020]. Disponível em https://docomomo.org.br/wpcontent/uploads/2016/01/161_M24_RM-LeCorbusiervoyageur-ART_daniela_santos.pdf.

SANTOS, Rui Afonso - O Primeiro e o Segundo Modernismos, in Lapa, Pedro; Tavares, Emilia (coord.) - Arte Portuguesa do Século XX - 1910-1960. Lisboa: MNAC, 2011. ISBN: 978989-660-080-8. p. XXVII-XXXVI.

SILVA, Bárbara - Brasil, La reinvención de la Modernidad. Le Corbusier, Lucio Costa, Oscar Niemeyer [Texto policopiado]. Madrid: Universidad Politécnica de Madrid, 2015. Dissertação de Doutoramento.

TSIOMIS, Yannis (org.) - Conférences de Rio, Le Corbusier au Brésil - 1936. Paris: Flammarion, 2006. ISBN: 978-2-0891-1610-8. ISBN: 978-2-0801-1610-9.

WALDMAN, Thaís Chang - Espaços de Paulo Prado: tradição e modernismo. Revue Artelogie, Dossier thématique: Brésil, questions sur le modernisme, № 01. 2011. [23 Junho 2020]. Disponível em http://cral.in2p3.fr/artelogie/spip.php?article66.

WEBER, Nicholas Fox - Le Corbusier (A Life). Nova lorque: Alfred A. Knopf, 2008. ISBN: 9780-375-41043-7.

ZAKIA, Silvia Palazzi - Primeira visita de Le Corbusier ao Brasil em 1929. Uma chegada acidentadíssima!. Vitruvius, ano 09. setembro 2015. [23 junho 2020]. Disponível em https://www.vitruvius.com.br/revistas/read/arquiteturismo/09.102/5685.

\section{Biografia:}

João Belo Rodeia (PT), arquiteto, crítico e curador de arquitetura, membro da AICA-Portugal (Associação Internacional dos Críticos de Arte) e da EAHN-Rede Europeia de História da Arquitetura (European Architectural History Network), professor no Departamento de Arquitetura da Universidade Autónoma de Lisboa, membro dos conselhos consultivos do DOCOMOMO International, da Trienal de Arquitetura de Lisboa (comissário científico da primeira edição) e da Galeria de Arquitetura NOTE, especialista externo do Prémio Mies van der Rohe - União Europeia, membro dos júris do Prémio AICA (2018) e do Prémio Secil de Arquitetura (2019). Foi Presidente da Ordem dos Arquitetos (OA) e do Instituto Português de Património Arquitetónico (IPPAR). Vive em Lisboa. 